\title{
Assessment of patient knowledge of diabetic goals, self-reported medication adherence, and goal attainment
}

\author{
Heather P. WHITLEY, Joli D. FERMO, Kelly RAGUCCI, Elinor C. CHUMNEY.
}

\begin{abstract}
${ }^{*}$
Background: Medication adherence is an integral aspect of disease state management for patients with chronic illnesses, including diabetes mellitus. It has been hypothesized that patients with diabetes who have poor medication adherence may have less knowledge of overall therapeutic goals and may be less likely to attain these goals.

Objective: The purpose of this study was to assess self-reported medication adherence, knowledge of therapeutic goals (hemoglobin A1C [A1C], low density lipoprotein cholesterol [LDL-C] and blood pressure $[\mathrm{BP}])$, and goal attainment in adult patients with diabetes.

Methods: A survey was created to assess medication adherence, knowledge of therapeutic goals, and goal attainment for adult patients with diabetes followed at an internal medicine or a family medicine clinic. Surveys were self-administered prior to office visits. Additional data were collected from the electronic medical record. Statistical analysis was performed.

Results: A total of 149 patients were enrolled. Knowledge of therapeutic goals was reported by $14 \%, 34 \%$, and $18 \%$ of survived patients for LDL-C, $\mathrm{BP}$, and $\mathrm{A} 1 \mathrm{C}$, respectively. Forty-six percent, $37 \%$, and $40 \%$ of patients achieved LDL-C, BP, and A1C goals, respectively. Low prescribing of cholesterollowering medications was an interesting secondary finding; $36 \%$ of patients not at LDL-C goal had not been prescribed a medication targeted to lower cholesterol. Forty-eight percent of patients were medication non-adherent; most frequently reported reasons for non-adherence were forgot $(34 \%)$ and too expensive (14\%). Patients at A1C goal were more adherent than patients not at goal $(p=0.025)$. Conclusion: The majority did not reach goals and were unknowledgeable of goals; however, most were provided prescriptions to treat these parameters. Goal parameters should be revisited often amongst multidisciplinary team members with frequent and open communications. Additionally, it

\footnotetext{
*Heather P. WHITLEY. PharmD, BCPS. Department of Pharmacy Practice, Auburn University Harrison School of Pharmacy and Department of Community and Rural Medicine, University of Alabama School of Medicine, Tuscaloosa, Alabama (USA).

Joli D. FERMO. PharmD, BCPS, BC-ADM, CDE.

Department of Pharmacy and Clinical Sciences, South Carolina College of Pharmacy. South Carolina (USA). Kelly RAGUCCI. PharmD, FCCP, BCPS, CDE.

Department of Pharmacy and Clinical Sciences, South Carolina College of Pharmacy. South Carolina (USA). Elinor C. CHUMNEY. PhD. Department of Pharmacy and Clinical Sciences, South Carolina College of Pharmacy. South Carolina (USA).
}

\author{
is imperative that practitioners discuss the \\ importance of medication adherence with every \\ patient at every visit.
}

Keywords: Patient Compliance. Diabetes Mellitus. Comprehension. Treatment Outcome. United States.

\section{RESUMEN}

Antecedentes: La adherencia al tratamiento es un aspecto integral de la gestión de la enfermedad para pacientes con enfermedades crónicas, como la diabetes mellitus. Se ha sugerido que los pacientes con diabetes que tienen baja adherencia a la medicación pueden tener peor conocimiento de los objetivos terapéuticos generales y puede ser menos probable que los alcancen.

Objetivo: El propósito de este estudio fue evaluar la adherencia auto-comunicada a la medicación, el conocimiento de los objetivos terapéuticos (hemoglobina A1C [A1C], lipoproteinas de baja densidad [LDL-C] y presión arterial), y la consecución de objetivos en adultos con diabetes. Métodos: Se creó un cuestionario para evaluar la adherencia a la medicación, el conocimiento de objetivos terapéuticos, y la consecución de objetivos para adultos con diabetes seguidos en un departamento de medicina interna o de medicina de familia. Los cuestionarios se entregaron antes de la visita a la clínica. Se recogieron datos adicionales de las historias clínicas electrónicas. Se realizó un análisis estadístico.

Resultados: Se incluyó un total de 140 pacientes. El conocimiento de los objetivos terapéuticos fue comunicado por el $14 \%, 34 \%$ y $18 \%$ de los pacientes encuestados para LDL-C, PA y A1C, respectivamente. El $46 \%$, el $37 \%$ y el $40 \%$ de los pacientes alcanzó los objetivos de LDL-C, PA, y A1C, respectivamente. La baja prescripción de hipolipemiantes fue un hallazgo secundario interesante; el 36\% de los pacientes no tenían prescrito un medicamento para bajar el colesterol. El 48\% de los pacientes eran incumplidores; los motivos más frecuentemente comunicados para incumplir fueron el olvido (34\%) y demasiado caro (14\%). Los pacientes en el objetivo de A1C eran más cumplidores que los que no estaban en el objetivo $(\mathrm{p}=0,025)$.

Conclusión: La mayoría no alcanza los objetivos y eran desconocedores de los objetivos; sin embargo, a la mayoría e les habían proporcionado medicamentos para tratar esos parámetros. Los parámetros objetivos deberían revisarse más a menudo entre los miembros del equipo 
multidisciplinario con comunicaciones abiertas y frecuentes. Además, es necesario que los facultativos discutan la importancia del cumplimiento de la medicación con capa paciente en cada visita.

Palabras clave: Cumplimento. Diabetes mellitus. Comprensión. Resultados del tratamiento. Estados Unidos.

\section{(English)}

\section{INTRODUCTION}

Diabetes is a chronic illness that requires continuous medical care and patient education in order to prevent microvascular and macrovascular complications. Nearly 21 million people in the United States have this disease and it remains the most common cause of blindness, kidney failure, and amputations in adults. Furthermore, the risk of heart disease and stroke is two to four folds greater among people with diabetes. ${ }^{1}$ At least 65 percent of people with diabetes will die from a heart attack or stroke, yet many individuals remain unaware of these risks. ${ }^{2}$ Recent randomized controlled trials have emphasized the importance of goal attainment in order to prevent these long-term complications of both type 1 and type 2 diabetes. ${ }^{3-6}$

According to the American Diabetes Association, the target for long-term glycemic control in patients with diabetes is a A1C value of less than $7 \%{ }^{7}$ Since patients with diabetes are at increased risk for cardiovascular events, additional treatment goals include achieving BP less than $130 / 80 \mathrm{mmHg}$ and LDL-C less than $100 \mathrm{mg} / \mathrm{dL}$ (or less than $70 \mathrm{mg} / \mathrm{dL}$ for those at "very high risk"). ${ }^{7-10}$ Limitations to patients achieving these goals may include underutilization of medications, poor medication adherence, under appreciation of goal attainment importance, or lack of goal knowledge. The purpose of this study is to assess patients' knowledge of therapeutic goals, self-reported adherence to goalrelated medications, and attainment of therapeutic goal targets (A1C, LDL-C, and BP) in adult patients with diabetes mellitus.

\section{METHODS}

A standardized survey was created for adult patients ( $\geq 18$ years of age) with type 1 or type 2 diabetes in order to assess their knowledge of therapeutic goals, medication adherence, and goal attainment (Appendix 1). Survey questions were derived from Morisky, et al in an effort to provide an additional level of validity. ${ }^{11}$

The study was conducted between October 2005 and March 2006 at two primary care clinics where family medicine and internal medicine attending and resident physicians practice. The majority of patients followed at each of the clinics had multiple chronic disease states and many were indigent. All patients 18 years of age or older, who maintained a diagnosis of type 1 or type 2 diabetes, were eligible for inclusion if they were followed by a physician within either clinic. Exclusion criteria included age less than 18 years, pregnant, mentally impaired, or without a diagnosis of type 1 or type 2 diabetes. While in the waiting room, prior to the office visit, eligible patients self-administered the one-page survey and returned the completed survey to the clinical pharmacist.

Although definitions and goal values of $\mathrm{A} 1 \mathrm{C}, \mathrm{BP}$, and cholesterol were not explained to patients until after the survey was completed, so as to decrease bias, the clinical pharmacist was available if questions arose. This often provided the opportunity to educate patients and identify adherence problems. Patients with known or discovered low literacy levels were offered help reading and completing the survey. These functions were performed in an effort to increase survey validity by ensuring patient comprehension of survey questions and to eliminate errors due to misunderstanding.

Demographic information and objective data, including prescribed medications, were collected from the electronic medical record and entered into a Microsoft Access database and analyzed with StataTM statistical software (Stata Corporation, College Station, TX). For analysis, patient survey answers of "not sure" were equivalent to "no." A series of analyses to investigate the relationships between patient survey responses and objective data recorded in the electronic medical record was conducted. Pearson correlation coefficients were used to examine pair wise relationships in the data. T-tests were used to compare differences in adherence levels between those who did and did not attain various clinical goals.

The Institutional Review Board at the Medical University of South Carolina (MUSC) approved this study; all patients provided consent to participate. All collected data was kept in a locked drawer in the primary investigator's office. Only the primary and co-investigators had access to the collected information and all published results were deidentified to further ensure patient confidentiality. Actions to ensure patient confidentiality were discussed with each patient during the review of informed consent.

\section{RESULTS}

A total of 149 patients were enrolled in the study, all of whom completed the survey. All were diagnosed with type 2 diabetes; by chance no patient had a diagnosis of type 1 diabetes. Three quarters of patients were female $(n=112)$, the average age was 61 years, and $77 \%(n=114)$ were African American. Average BP was $136 / 71 \mathrm{mmHg}(37 \%, \mathrm{n}=55$ at goal of $\leq 130 / 80 \mathrm{mmHg})$, average A1C was $8.1 \%(40 \%$, $\mathrm{n}=59$ at goal of $\leq 7 \%$ ), and LDL-C was $105 \mathrm{mg} / \mathrm{dl}$ $(46 \%, n=69$ at goal of $\leq 100 \mathrm{mg} / \mathrm{dl})$. Eighty-eight percent of patients $(n=131)$ were taking at least one antihypertensive medication, 69\% ( $n=103)$ were taking a medication for hyperlipidemia, and $83 \%$ $(n=124)$ were using medication to control diabetes; $44 \%(n=66)$ were using an oral antidiabetic agent as monotherapy, $16 \% \quad(n=24)$ using insulin as 
monotherapy, and $23 \% \quad(n=34)$ were using combination therapy with oral agents and insulin. Of those patients who were not at goal and should have been taking medicine to control their condition, $9 \%$ ( $n=8$ of 94 not at BP goal) were not using any antihypertensive therapy, $36 \% \quad(n=29$ of 80 not at LDL-C goal) were not using a cholesterol-lowering agent, and $8 \%$ ( $n=7$ of 90 not at A1c goal) were not using either an oral agent or insulin to control blood glucose. Additional patient demographics are described in Table 1.

\begin{tabular}{|c|c|}
\hline \multicolumn{2}{|c|}{ Table 1: Patient Demographics $(n=149)$} \\
\hline Variables & Mean or \% (SD) \\
\hline \multicolumn{2}{|l|}{ Patient demographics } \\
\hline Male & $25 \%$ \\
\hline Age & $61(13.9)$ \\
\hline Caucasian & $22 \%$ \\
\hline African American & $77 \%$ \\
\hline Other & $1 \%$ \\
\hline \multicolumn{2}{|l|}{ Medication use } \\
\hline Antihypertensive therapy & $88 \%$ \\
\hline Hyperlipidemic therapy & $69 \%$ \\
\hline Oral antidiabetic therapy & $67 \%$ \\
\hline $\begin{array}{l}\text { Oral antidiabetic } \\
\text { monotherapy }\end{array}$ & $44 \%$ \\
\hline Insulin therapy & $46 \%$ \\
\hline Insulin monotherapy & $16 \%$ \\
\hline $\begin{array}{l}\text { Both oral and injectable } \\
\text { antidiabetic therapy }\end{array}$ & $23 \%$ \\
\hline $\begin{array}{l}\text { Either oral or injectable } \\
\text { antidiabetic therapy }\end{array}$ & $85 \%$ \\
\hline \multicolumn{2}{|c|}{ Patient clinical and treatment measures } \\
\hline SBP & $136(22.7)$ \\
\hline DBP & $71(11.4)$ \\
\hline $\mathrm{BP} \leq 130 / 80 \mathrm{mmHg}$ & $37 \%$ \\
\hline $\mathrm{A} 1 \mathrm{C}$ & $8.1(2.2)$ \\
\hline $\mathrm{A} 1 \mathrm{C} \leq 7 \%$ & $40 \%$ \\
\hline LDL-C & $105(35.7)$ \\
\hline LDL-C $\leq 100 \mathrm{mg} / \mathrm{dl}$ & $46 \%$ \\
\hline
\end{tabular}

Table 2 describes patient-reported knowledge of therapeutic goals and current levels. Overall, more patients reported knowing their therapeutic BP goal and current BP level (34\% and 39\% respectively) than their LDL-C and $\mathrm{A} 1 \mathrm{C}$ goals and levels. For those patients who attained their LDL-C, BP, or A1C goal, only 35,29 , and $33 \%$ reported knowledge of the respective therapeutic goal. Also of note, approximately one-fifth of patients reported knowledge of $\mathrm{A} 1 \mathrm{C}$ interpretation.

Although 14,39 , and $10 \%$ of patients reported knowledge of their A1C, BP, and LDL-C respectively, very few patients provided actual values in support, and only a portion of those reported values were accurate. Only 12 selfreported their current LDL-C, whereas 16 reported their A1C, 40 reported their systolic BP, and 37 reported their diastolic BP. Low or even negative correlations between the self-reported levels and those listed in medical records were detected. When comparing the patient-reported LDL-C with their actual LDL-C found in the electronic medical record, no correlation existed $(r=0.003)$. There was a surprisingly negative correlation between A1C values that patients reported on their survey and actual values recorded in the electronic medical record ( $r=-0.299)$. Correlation statistics between the patient-reported and actual BP values were more encouraging, with both demonstrating a relatively strong positive relationship ( $r>0.40)$ (See Table 3 ). This strong positive relationship could be attributed to a larger sample size for this portion of the analysis, with over 35 patients completing BP values on the survey.

Medication non-adherence was defined as patients self-reporting at least one reason for missed doses. By this definition, a total of 71 patients $(48 \%)$ were deemed to be non-adherent with their medications. In this population, the most frequently identified reasons for medication non-adherence included the following: forgetfulness (34\%), the patient felt better $(11 \%)$, medications too expensive $(14 \%)$, and other $(13 \%)$, as further described in Figure 1. Using a two-sample t-test, a significant positive relationship between the level of adherence and A1C goal attainment was found $(p=0.025)$. Patients at $A 1 C$ goal were more adherent on average (mean 0.49 , range 0-2 "yes" responses) than patients who did not reach A1C goal (mean 0.88, range 0-5 "yes" responses). The differences in adherence by BP goal ( 0.74 if attained goal and 0.66 if did not attain goal, $p=0.65$ ) or LDL-C goal (0.67 if attained goal and 0.76 if did not attain goal, $p=0.56$ ) were not significant.

Table 2: Patient-reported knowledge of therapeutic goals and current levels $(n=149)$

\begin{tabular}{|l|l|l|l|}
\hline \multicolumn{2}{|l|}{ Table 2: Patient-reported knowledge of therapeutic goals and current levels (n=149) } \\
\hline Reported knowing goal & LDL-C & BP & A1C \\
\hline Reported knowing level & $14 \%$ & $34 \%$ & $18 \%$ \\
\hline Reported understanding what an elevated A1C means & $39 \%$ & $14 \%$ \\
\hline
\end{tabular}

\section{DISCUSSION}

The patient population analyzed was representative of the larger diabetic population within South Carolina, as they were predominately African American with a similar mean age. ${ }^{12}$ Of interest, the majority of patients were not at LDL-C, BP, or A1C goal, although most were provided prescriptions to treat these parameters. Of those patients not at A1C or BP goal, only a small percent $(4 \%$ and $9 \%$, respectively) had not been prescribed medications to lower these values. Low prescribing of cholesterol-lowering medications, while not the focus of the study, was an interesting secondary finding; $36 \%$ of patients not at LDL-C goal had not been prescribed a medication targeted to lower cholesterol. Another study demonstrated more bothersome results; Fuke and colleagues analyzed diabetic patients with and without coronary heart disease to determine the proportion who attained LDL-C goal of $\leq 100 \mathrm{mg} / \mathrm{dl}$. The analysis showed that $68.8 \%$ of the population was not prescribed lipid-lowering drug therapy, and of that cohort, only $14.7 \%$ had attained LDL goal, leaving $85.3 \%$ of patients not reaching goal and still not using appropriate medication therapy. ${ }^{13}$ Together, these studies highlight the underutilization of LDL-C 
lowering therapy and the inappropriately low goal attainment among patients at greatest risk for

cardiovascular-related deaths.

\begin{tabular}{|l|l|l|l|}
\hline \multicolumn{2}{|l|}{ Table 3: Correlations between Patient-Reported and Actual Values } \\
\hline Variable & $\mathrm{n}$ & $\%$ & $\begin{array}{l}\text { Correlation } \\
\text { Statistic }\end{array}$ \\
\hline \multicolumn{2}{|l|}{ Patient-reported knowledge of therapeutic goals } & \\
\hline LDL-C & 142 & 95.3 & 0.0861 \\
\hline SBP & 141 & 94.6 & 0.1527 \\
\hline DBP & 141 & 94.6 & 0.1474 \\
\hline A1C & 135 & 90.6 & -0.0304 \\
\hline Patient-reported therapeutic goals & 9.4 & 0.0033 \\
\hline LDL-C & 14 & 15.4 & 0.2184 \\
\hline SBP & 23 & 13.4 & 0.0834 \\
\hline DBP & 20 & 10.1 & -0.3570 \\
\hline A1C & 15 & 94.0 & 0.0635 \\
\hline Patient-reported knowledge of current levels & -0.0781 \\
\hline LDL-C & 140 & 91.9 & -0.0022 \\
\hline SBP & 137 & 91.9 & -0.0880 \\
\hline DBP & 137 & 94.0 & \\
\hline A1C & 140 & & 0.0033 \\
\hline Patient-reported current levels & 8.1 & 0.4072 \\
\hline LDL-C & 12 & 26.8 & 0.4168 \\
\hline SBP & 40 & 24.8 & -0.2989 \\
\hline DBP & 37 & 10.7 & \\
\hline A1C & 16 & & \\
\hline
\end{tabular}

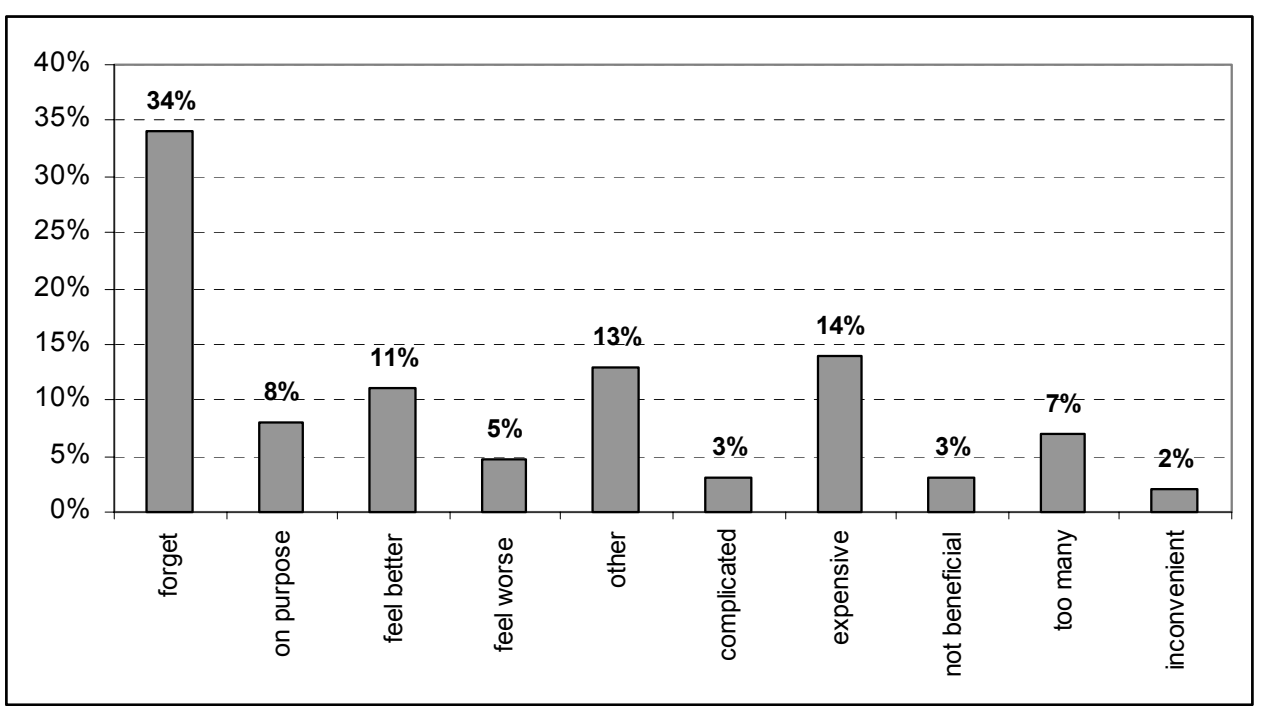

Figure 1. Patient self-reported explanations for missing doses $(n=71)$

One potential solution to increase appropriate prescribing of cholesterol therapy may be the development of a pharmacist managed cholesterol focused clinic. Since pharmacists are familiar with drug and disease state management, they are ideal clinicians for managing patients with dyslipidemia through such practices. ${ }^{14-16}$ Lipid management programs, headed by clinical pharmacists, increase the number of at-risk-patients identified for developing heart disease and allow pharmacists to educate patients about the implications of elevated cholesterol levels and methods to decrease high cholesterol. ${ }^{17}$ Studies have found a $26 \%$ and $27.7 \%$ decrease in LDL-C levels through pharmacist involvement in patients warranting primary and secondary prevention, respectively. ${ }^{18,19}$ Cording and colleagues demonstrated that implementation of a pharmacist-managed lipid clinic within a primary care medical clinic helped $77 \%$ of patients reach their LDL-C goal over a course of 12 months. ${ }^{20}$ Another potential solution to increase therapeutic goal attainment may include integration of a multidisciplinary team approach to patient care. Patients treated for dyslipidemia through a multidisciplinary team in an outpatient setting were four times more likely to attain their NCEP goal $(p<0.001)$ than those treated via traditional methods. ${ }^{21}$ Collectively, implementation of lipid management clinics and/or integration of multidisciplinary health care teams may improve prescribing of cholesterol-lowering medications, goal attainment, and ultimately mortality.

Lack of current value and therapeutic goal knowledge was also alarmingly low. Although between 10 and $39 \%$ of patients reported knowledge of therapeutic goals and current values, as low as $8 \%$ actually provided documentation of 
knowledge. One could interpret this lack of information as a knowledge deficit. It is hence appropriate to conclude that these patients frequently do not know the goals of therapy, and are unaware of their current A1C, LDL-C, or BP values. It is also worth mentioning that only one fifth of patients reported knowing the interpretation of $A 1 C$, although this was not demonstrated for verification. Therefore, patients may have not truly understood the meaning of $\mathrm{A} 1 \mathrm{C}$; thus, $20 \%$ could be an overestimation.

Interestingly, patients more frequently reported knowledge of BP than A1C and LDL-C goals. This could be attributed to the increased frequency of $\mathrm{BP}$ measurements, as it is evaluated at all visits and automated cuffs are often available for use at many pharmacies. Additionally, patients may be more familiar with their BP values and goals because results are immediately available and reported to patients after testing. LDL-C and A1C analysis, by contrast, are less frequently performed, as they require phlebotomy and thus, have greater lag times until results are available.

To increase the frequency of testing and decrease lag time to result obtainment the addition of point-ofcare (POC) instruments to test $A 1 C$ and LDL-C may prove useful. Use of POC tests are expanding rapidly at $12-15 \%$ annually. ${ }^{22}$ Specifically, ambulatory care clinical pharmacists equipped with a POC test could readily assess lipid and A1C levels, provide results and education to the patient, and make necessary therapeutic changes targeted to patient-specific goals. ${ }^{23}$ Studies demonstrate POC testing used by pharmacists improve patient compliance with medication regimens ${ }^{17}$, while others have noted that therapeutic decision-making, goal attainment, and treatment outcomes are enhanced. ${ }^{24,25}$ In turn, use of this type of technology by clinical pharmacists may increase dose titration, improve patient knowledge and perceived importance of goal achievement, and facilitate LDL$\mathrm{C}$ and $\mathrm{A} 1 \mathrm{C}$ goal attainment.

When comparing self-reported medication adherence to target goal attainment, a significant positive relationship was found between the level of adherence and A1C goal attainment. On the other hand, there appeared to be no relationship between medication adherence and control of BP or LDL-C. A plausible explanation for this discrepancy could be the reliability of measurement and confounding factors. A1C reflects patient control of blood glucose over several months and has very few acute confounders. Conversely, both BP and LDL$\mathrm{C}$ are easily influenced by alterations in weight, diet, and exercise. Additionally, BP readings are more easily affected by acute variables such as stress, pain, caffeine intake, smoking, and variability induced by appropriate measurement techniques. Such confounders, including appropriate method of testing BP, were not controlled during this analysis.

Forgetfulness was the most frequently reported reason for medication non-adherence, followed by medications being too expensive, and patients feeling better. Poor adherence to medications contributes to morbidity, mortality, and increased health care costs. ${ }^{26}$ However, given the need for these patients to take a variety of medications, with different dosage frequencies and numbers of tablets at various times of the day, it is not surprising that non-adherence occurs. Several studies have already demonstrated this point. ${ }^{27,28}$

As healthcare providers, we can help patients overcome some of these obstacles that lead to medication non-adherence. Osterberg and Blaschke advised practitioners to always assess for poor adherence. $^{26}$ They recommended providers emphasize the importance of the medication regimen, make the regimen simple, and customize the regimen to the patient's lifestyle. Additionally, we can aid patients in identifying methods to help them remember to take their medication, and thus improve adherence. Per our patient population, this may include simple changes, such as moving the time various medications are administered or using reminders to tie daily activities to medication use. Beyond the use of a standard weekly pill box, more advanced technology could include the use of pill boxes with audible reminders and digital alarm clocks on cellular phones or personal digital assistance devices. ${ }^{26}$ Approximately $14 \%$ of assessed patients complained of poor adherence due to the expense of medication regimens. As healthcare providers, it is essential to consider the patient's ability to afford prescriptions prior to adding new medications. Likewise, it is important to identify poor medication adherence due to cost. Regimens should be altered to provide therapeutic options at lower cost, such as switching from brand to generic or a generic class equivalent when possible. It is important to advise these patients that there may not be a less expensive alternative in a once-a-day formulation. In this case, cost versus benefit must be assessed. Lastly, practitioners should frequently remind patients that maintenance medications for chronic disease states, such as hypertension, diabetes, and hyperlipidemia, are not to be discontinued when they feel better or once therapeutic goals are reached. The more information and understanding that patients have regarding their disease states and pharmacologic therapies, the more likely they are to adhere to those therapies. ${ }^{29}$ The authors, Hsaio and Salmon, strongly believe that patients who are most likely to respond and reach goals are those who are willing to make behavioral changes and take responsibility for their own health care. Therefore, adequate follow-up, motivation and empowerment techniques are increasingly important.

There are limitations to this investigation. Since patients were completing a self-reported survey, recall bias may have induced error. The potential inability to correctly remember reasons for medication non-adherence could potentially skew the data. Secondly, patients were surveyed at varying time points after the diagnosis of diabetes, and the number of interactions with healthcare professionals concerning diabetes management was not assessed. One would anticipate that patients who had been diagnosed with diabetes and had several appointments with a clinical diabetes educator may have greater knowledge and better 
control of their disease state than would a newly diagnosed individual. Although the authors cannot assume that these findings could be generalized to the population at large, including those with type 1 diabetes, our patient population does seem to be typical of patients with type 2 diabetes, as they also suffered from hypertension and hyperlipidemia.

\section{CONCLUSIONS}

In addition to providing insight into patients' knowledge of diabetic therapeutic goals, the information gained from this study has several implications for clinical practice. First, it is evident by the data gathered in previous trials, and confirmed by this study, that patients are frequently not reaching therapeutic goals; however, most were provided prescriptions to treat these parameters. Unfortunately, a large proportion of patients who had not attained LDL-C goal still were not prescribed appropriate medications to target cholesterol. Additionally, patients were frequently unaware of therapeutic goals and almost half were medication non-adherent. Actions may be taken to improve these aspects of patient knowledge, adherence, and goal attainment may include addition of POC testing devices, implementation of pharmacy driven clinics, or functioning within multidisciplinary teams. Regardless of implemented actions, it is imperative that practitioners discuss the importance of medication adherence with every patient at every visit. Together the implementation of these three actions may better help patients achieve therapeutic targets and avoid unnecessary microvascular and macrovascular complications.

\section{ACKNOWLEDGEMENTS}

The authors acknowledge the contributions of Laura Foxhall, RN, Medical University of South Carolina and Bart Lawrence, PharmD, Pfizer Inc.

\section{References}

1. Centers for Disease Control and Prevention. National diabetes fact sheet: general information and national estimates on diabetes in the United States, 2005. Atlanta, GA: U.S. Department of Health and Human Services, Centers for Disease Control and prevention, 2005.

2. American Diabetes Association. Available from: http://www.diabetes.org/home.jsp. (Accessed January 19, 2006).

3. The Diabetes Control and Complications Trial Research Group, The Effect of Intensive Treatment of Diabetes on the Development and Progression of Long-Term Complications in Insulin-Dependent Diabetes Mellitus. N Engl J Med 1993;329:977-986.

4. Stratton IM, Adler AI, Neil HAW, et al. Association of glycaemia with macrovascular and microvascular complications of type 2 diabetes (UKPDS 35): prospective observational study. BMJ 2000;321:405-12.

5. Adler Al, Stratton IM, Neil HAW, et al. Association of systolic blood pressure with macrovascular and microvascular complications of type 2 diabetes (UKPDS 36): prospective observational study. BMJ 2000;321:412-9.

6. DCCT/EDIC Study Research Group. Intensive diabetes treatment and cardiovascular disease in patients with type 1 diabetes. N Engl J Med. 2005;353(25):2643-53.

7. Standards of Medical Care in Diabetes-2006. American Diabetes Association. Diabetes Care 2006;29:S4-42.

8. Chobanian AV, Bakris GL, Black HR, et al, and the National High Blood Pressure Education Program Coordinating Committee. Seventh Report of the Joint National Committee on Prevention, Detection, Evaluation, and Treatment of High Blood Pressure. Hypertension 2003;42:1206-52.

9. Executive Summary of the Third Report of the National Cholesterol Education Program (NCEP) Expert Panel on Detection, Evaluation, and Treatment of High Blood Cholesterol in Adults (Adult Treatment Panel III). Expert Panel on Detection, Evaluation, and Treatment of High Blood Cholesterol in Adults. JAMA 2001;285:2486-97.

10. Zhou J, Werstuck GH, Lhoták S, et al. Association of multiple cellular Stress Pathways with accelerated atherosclerosis in hyperhomocysteinemic apolipoprotein E-deficient mice. Circulation 2004;110:227-39.

11. Morisky DE, Green LW, Levine DM. Concurrent and predictive validity of a self-reported measure of medication adherence. Medical Care 1986;24(1):67-74.

12. Department of health and environmental control (DHEC). Burden of diabetes in South Carolina 2003. Diabetes initiative of South Carolina. 2003:26.

13. Fuke D, Hunt J, Siemienczuk J, et al. Cholesterol Management of Patients With Diabetes in a Primary Care PracticeBased Research Network. Am J Manag Care 2004;10(2):130-136.

14. Furmaga E. Pharmacist management of a hyperlipidemia clinic. Am J Hosp Pharm 1993;50:91-5.

15. Ito M. Should hyperlipidemia in the elderly be treated? Am J Health-Syst Pharm 1993;53:2867-71.

16. MacKinnon G. Hyperlipidemia management: opportunity for pharmacists in community practice. Pharm Times 1998;Dec:24-39.

17. Jafari M, Masih M, Emerson JF. The value of pharmacist involvement in a point-of-care service, walk-in lipid screening program. Pharmacotherapy 2001;21(11):1403-1406.

18. Ching Lee SS, Cheung PP, Chow MSS. Benefits of individualized counseling by the pharmacist on the treatment outcomes of hyperlipidemia in Hong Kong. J Clin Pharmacol 2004;44:632-639.

19. Carson J. Pharmacist-coordinated program to improve use of pharmacotherapies for reducing risk of coronary artery disease in low-income adults. Am J Health-Syst Pharm 1999;56:2319-24.

20. Cording MA, Engelbrecht-Zadvorny EB, Pettit BJ, Eastham JH, Sandoval R. Development of a pharmacist-managed lipid clinic. Ann Pharmacother 2002;36:892-904. 
21. Shaffer J, Wexler L. Reducing low-density lipoprotein cholesterol levels in an ambulatory care system: results of a mulitdisiplinary collaborative practice lipid clinic compared with traditional physician-based care. Arch Intern Med 1995; 155:2330-5.

22. Kost GJ. Preventing medical errors in point-of-care-testing security, validation, performance, safeguards, and connectivity. Arch Pathol Lab Med 2001;125:1307-15.

23. Taylor JR, Lopez LM. Cholesterol: Point-of-care testing. Ann Pharmacother 2004;38:1252-7.

24. Gutierres SL, Welty TE. Point-of-care testing: an introduction. Ann Pharmacother 2004;38:119-25.

25. Kennedy L, Herman WH, Strange P, Harris A. GOAL AIC Team. Impact of active versus usual algorithmic titration of basal insulin and point-of-care versus laboratory measurement of $\mathrm{HbA} 1 \mathrm{c}$ on glycemic control in patients with type 2 diabetes: the Glycemic Optimization with Algorithms and Labs at Point of Care (GOAL A1C) trial. Diabetes Care 2006;29(1):1-8.

26. Osterberg L, Blaschke T. Adherence to medication. N Engl J Med 2005;353:487-97.

27. Reasner CA, Goke B. Overcoming the barriers to effective glycemic control for type 2 diabetes. Br J Diabetes Vasc Dis 2002;2:290-5.

28. Blandford L, Dans PE, Ober JD, Wheelock C. Analyzing variations in medication compliance related to individual drug, drug class, and prescribing physician. J Managed Care Pharm 1999;5:47-5.

29. Hsaio LD, Salmon JW. Predicting adherence to prescription medication purchase among HMO enrollees with diabetes. J Managed Care Pharm 1999;5:336-41. 


\section{APPENDIX 1. SURVEY FOR PATIENTS WITH DIABETES}

Please answer questions below.

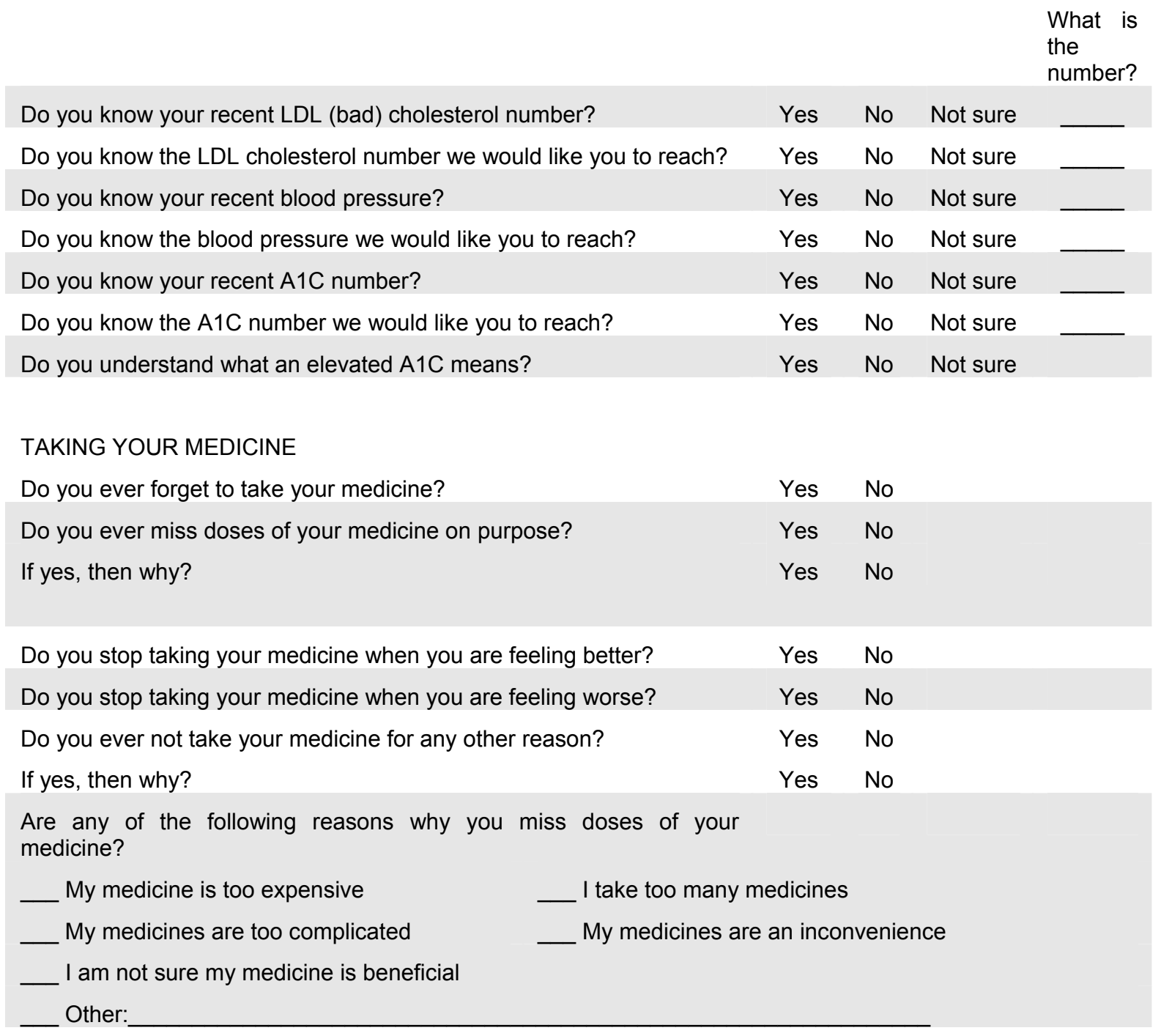

\section{FOR OFFICE USE ONLY}

Chart \#: Gender: M/F Ethnicity: AA Cauc Hisp Asian Oth A1C: (at goal? Y N)

Date: Age:

LDL-C: (at goal? Y N)

BP: (at goal? Y N)

Active medicine for: BP LDL-C oral diabetes med insulin 